\title{
CONSIDERING INTERNAL SPACE LAYOUT AS A MAJORE COMPONENT OF VISUAL ANALYSIS FOR URBAN SYSTEMS AND A KEY TO REINTERPRET URBAN STRUCTURES
}

\author{
D. Fisher-Gewirtzman \\ Faculty of Architecture \& Town Planning, Technion - IIT, Haifa, Israel \\ Commission IV, WG 8
}

KEY WORDS: Architecture, Design, Sustainable, Environment, Geometry, Configuration, Building, Visualization

\begin{abstract}
:
Reviving neglected existing urban fabrics is one of the main frame-work for our future. A contemporary theory of conservation regarding architectural intervention and buildings subsequent re-use, has been developed to address a growing number of tired and neglected buildings. Rehabilitation is required for buildings that are no longer fit to purpose and struggling to adapt a new use. The Spatial Openness Index, is a visibility analysis model defined as the volume of the visible part of a surrounding sphere: the potential of a view and exposure that can indicate on the Perceived Density. Using visibility analyses models and tools, regarding internal space layout, in reinterpreting the functional use of existing buildings would contribute to future refurbishment and reviving urban fabrics. In this paper, a study of the relation between internal space layout and functionality and external visual analysis is suggested. The study is demonstrated on a neglected Haifa neighborhood.
\end{abstract}

\section{INTRODUCTION}

\subsection{Regenerating City Fabrics by Reusing Existing structures}

For some times the discussion amongst Planners, Designers and many public personalities regarding urban renewal has enlightened the fact that it is a central component for sustainable development and as a key for promoting existing cities (Carmon, 2008). Although for a long period many believed that the regenerating potential is concealed in evacuation/clearance and then new development. The issue of whether to demolish or refurbish older housing has been debated for over a century. In the UK it has been active policy area since late 1880, when government first authorized demolition of slums. Some years ago the Environmental arguments about renovating the existing built stock have gained increasing prominence as people have sought to defend their communities from demolition (Power A., 2008). Sustainable development commission in London argues the urgent need to update the existing built stock on the grounds that $70 \%$ of all homes that will exist in 2050 are already built (power A, 2008). The benefits of refurbishing is in the reduction of landfill disposal, greater reuse of materials, reuse of infill sites and existing infrastructures, reduced new buildings, local economic development, retention of community infrastructure, neighbourhood renewal and management. Updating existing structures is likely to gain in significance for environmental, social and economic reasons. Adopting policies that aid the retention and upgrading of the existing built stock will help develop the necessary skills and technologies, save materials and land, and enhance the integration of existing communities in need of regeneration (Power A., 2008).

\subsection{Up-Dating Dwellings}

Updating dwelling is defined as editing significant changes to old apartments and condominiums to accepted standards in current new building construction (regarding multi dwelling in large building compounds and not private homes). The initiative to such changes and the responsibility to implement them is many times in the hand of the owners, matching their dwelling space to their needs and preferences, regarding their economic means. Only rarely, private entrepreneurs take part in this process. This is a long term process that should repeat itself every period, at least every 30 years, to adjust dwellings to current times (Carmon, 2008). Updating accommodations many times includes two to four of the following actions: Change in the dwelling size, Significant change in the internal planning and design of the dwelling unit, renovation building facades and yards and the fourth is inserting additional functions to the building or substantial transformation in existing functions, such as adding an elevator (Carmon, 2008).

A thorough study about updating dwellings in Israel can be found in Carmon 2008. Carmon points out the fact that many built compounds in Israel already need regeneration although most of them were built quite recently. She explains that the reason may be attached to the fact that most of the dwelling units were developed in very short time to address a large capacity of immigrants and for very low budget that derived in very low standard of building and very small apartments. In order to be able to fit today's standard these dwelling units and built compounds must go through massive change. Our study consists on neglected dwelling units where most of them must be updated to fit current needs and standard of life.

\section{QUANTITIVE MODELS AND TOOLS}

2.1 The Need for Quantified Measure of Subjective Variables in Dense Environments

Researchers have long ago distinguished the objective density from the subjective one. Rapoport (1975 defined perceived density as the perception of number of people in a given area, and of the available space and of its organization. Stokols (1972) distinguished between density as a physical description of people in relation to a given amount of space, and crowding, 
which he defined as a psychological or subjective experience derived from the recognition that one has less space than desired. What made his work so important was the understanding that crowding is a subjective phenomenon. Subsequently, crowding was defined as a stressful situation that sometimes appears along with high objective density (Sundstorm, 1978). Several studies tried to identify the relationships between objective density and crowding, (Evans \& Lepore, 1998), or residential density. The efforts were directed into identifying the contributing personal and physical factors, as well as the interplay between them. Mitrany (2002) demonstrates the complicated relationships that exist between the objective density, the perceived density and the quality of life, where high density is not always correlated with crowding. Well documented, privacy is an important variable in maintaining well-being in high-density environments (Altman, 1975). Privacy from visual intrusion by strangers (from streets, for example) has been found to be important. Furthermore, privacy of neighbors in the same building or in adjacent ones from each other was found to be a salient kind of privacy (Mitrany, 2002). Privacy inside the apartment is achieved through the spatial arrangement of the buildings and the distances between buildings. The placement of the buildings should enable an open view from as many windows of each apartment as possible (Mitrany \& Churchman, 2004). The results of the study indicated the importance of spatial openness from one's apartment to the view as a physical variable that affect the evaluation of the density made by residents, as well as other physical variables that contribute to privacy at home. Although researchers in the field of environmental psychology has paid a fare amount of attention to the subjective aspects of high density, they still lack the ability to transfer the existing knowledge to quantified tools that planners and architects can use in order to accurately assess the impact of densification on residents.

\subsection{Visual Analysis Models and Tools}

Visibility characteristics are an important attribute in high density urban environments and might influence their economic attractiveness. High permeability to a view is one of the main objectives in the development of dense urban areas. It can influence the resident's satisfaction and the real estate value. In addition, Visual Exposure, referring to privacy, is also a major aspect influencing quality of the human environment. The 'Spatial Openness Index' (SOI) is a visibility analysis model that is specified in terms of three-dimensional visual spatial information, which is defined as the volume of the visible part of a surrounding sphere. SOI measurements in alternative spatial configurations were correlated with the comparative Perceived Density (Fisher-Gewirtzman at al 2003), thus, the objective measurements indicated a subjective response. Combining these three important factors (The Spatial Openness indicating on the perceived density, the Openness to the view and the Visual Exposure - referring to visual privacy), and being able to measure and evaluate them in one model is of a great importance that can support maintaining existing urban environments while developing sustainable urban environments. If designers will acquire knowledge of how to simultaneously preserve low levels of visual exposure (in a positive sense as related to privacy) and high levels of visual openness to the view for the residents in an urban environment, the satisfaction of residents with their urban environment will grow (Feitelson, 1990; Oh et al; 2002, Al-Kodmany, 2000). Recently there has been a revival of interest in visibility analysis of architectural configurations. Some of the current methods and automated models for visual analysis are summarized as follows: An 'isovist' is the area directly visible form any location within the space. Benedikt (1979) was the first to introduce the 'isovist' and to develop a set of analytic measurements of isovist properties to be applied in order to achieve quantitative descriptions of spatial environment (from Turner, 2001). A number of researchers have developed measurement methods and tools for automated isovist analysis, amongst them Turner et al. (2001) that showed how a set of isovist can be used to generate a graph of mutual visibility between locations. As a continuation, they have developed an automated model the Depthmap for visibility graph analysis. Batty (2001) describes how a set of isovist forms a visual field whose extent defines different isovist fields of different geometric properties. He suggested a feasible computational scheme for measuring isovist fields and illustrates how they can visualize their spatial and statistical properties by using maps and frequency distributions. Several automated models have been developed in order to examine the 'isovist' in different ways. Such as: the 'Spatialist' by Peponis et al (1998), and the 'Axman' by Bin Jiang (1999). Several methods show that visibility is connected to accessibility. For example, the Space Syntax method (Hillier, 1996) that examines the relation between spatial configurations and movement, and connects them with the social, cultural and economic-functional aspects.

Currently, visibility analysis models for urban systems look at the external space extended from buildings' façades without concerning the internal space layout. Some analysis models look at façade openings, in a very schematic way, regardless the internal space layout and functionality. Different internal functions and activities demand different levels of privacy and can enjoy differently openness to the view. As an example, the assumption is that in dwellings the living room and bed rooms require different levels of privacy and different levels of openness to external view. Also, offices require less privacy regarding external exposure than dwellings. This is of course, reliant upon human factors such as culture, society, age, gender exc. Another example is that locating bedrooms in dwellings on ground floor may suffer from visual exposure but commerce would enjoy greatly the same exposure. Investigating the internals' space layout is a major theme and combining space layout and functionality parameters into visual analysis models may contribute to broaden and precise the knowledge in this extremely important field and help support a sustainable urban environment.

\subsubsection{The Spatial Openness Index (SOI)}

The SOI - Spatial Openness Index - which can also be described as a 'three-dimensional isovist, can explore the threedimensional visibility and permeability of spatial configurations (as illustrated in figure 1 and 2), while enabling the ranking of alternative configurations by measuring the visible volume of the open space. It was the first real attempt to simulate human three dimensional visual perception (Fisher-Gewirtzman and Wagner, 2006; Fisher-Gewirtzman and Wagner, 2003). SOI measurements in alternative spatial configurations were correlated with the comparative perceived density (FisherGewirtzman et al., 2003), thus, the objective measurements indicated a subjective response. The measurements were carried out on alternative abstract configurations in the same volumetric density while the participants responded to virtual images. The SOI measurements have not yet been tested on realistic urban environments, and were not yet correlated with resident's subjective response. 


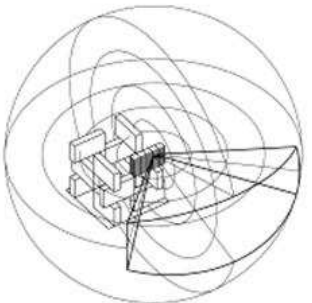

Figure 1: Spatial Openness Index (SOI) is defined as the volume of the part of a surrounding sphere which is visible from a given point of view.(Fisher-Gewirtzman\&Wagner, 2003).

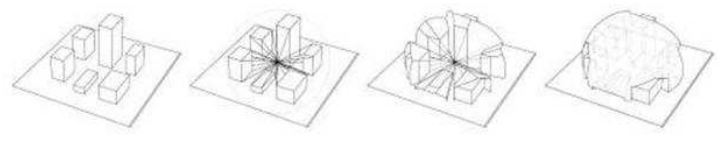

Figure 2: Spatial openness Index (SOI) for the public spaces is defined as the potential view captured from the viewpoint positioned between the buildings. The SOI is defined as the measured volume of space, which is visible from the indicated point of view.(Fisher-Gewirtzman et al. 2005).

A preliminary automated model, which enabled the measurement of Spatial Openness for alternative spatial configurations within predefined constraints, was developed via the collaboration of architecture and computer science researchers (Fisher-Gewirtzman and Wagner, 2003). This automated SOI model explores the visibility and permeability of spatial configurations, and enables the ranking of alternative spatial configurations. Alternatives are ranked by the measured volume of space potentially observed from given viewpoint inside buildings from "windows" looking out to the space around and from the public domain (the public spaces inbetween buildings). It enables the simulation of virtual landscapes, enabling a more realistic estimation of the quality of the view (for instance, coastal views as opposed to industrial views). (Fisher Gewirtzman and Wagner, 2006).This research effort does not intend to refer to specific components of the view or to view classification. This in itself demands an independent study.

\subsubsection{The Visual Exposure and Visual Openness}

Visual openness and visual exposure may appear to be contradictory terms. Visual openness would be considered as an advantage, insofar as views are longer and further away, and are measured by long distances; visual exposure, on the hand, is defined and measured by short viewing distances as illustrated in figure 3.

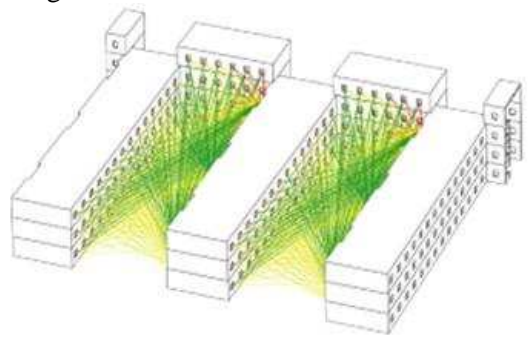

Figure 3: Visual Exposure As measured at Bat-Galim neighborhood, Length of view-lines for every window to other windows on every level (Shach-Pinsley et al., 2007, FisherGewirtzman, 2009).
Visual exposure refers to privacy aspects in the built environment, and is defined as the visual penetration into one's privacy as a result of being viewed from the external spaces of other building façades or from public spaces at street level. Most relevant precedent research regarding visual exposure has been based on qualitative methods. The concept of 'visual exposure' is part of the definition of 'visual privacy (Newell 1995). This research does not deal with the privacy issue or with the issue of 'visual privacy', but instead focuses on the concept of 'visual exposure' only, As to visual exposure, Archea (1977) evaluated environmental and behavioural aspects, and argued that 'visual access', the ability to monitor one's surroundings by sight, together with 'visual exposure', the probability that one's behaviour can be monitored by sight from one's surroundings, are the most fundamental attributes that subsume both environmental and behavioural aspects. The most dominant attribute found in the literature affecting visual exposure is distance between buildings (Al-Kodmany, 1999; Merry, 1987; Day, 2000). However, there is no approach that systematically classifies distances between buildings in relation to visibility. Al-Kodmany (2000) and Day (2000) argued that the arrangements of buildings of different heights could greatly disturb visual privacy. Also, Al-Kodmany (2000), Day (2000), and Asif and Malis (1998), argued that the height and location of facade openings in relation to those in adjacent buildings is critical to visual exposure.

Visual openness to the view is defined as the measured landscape area being viewed, i.e., the isovist area (Benedikt, 1979). Several researchers have studied visual openness to the view in urban environment. For example, Gibson (1974) argued that visual perception does not require information processing, and that it is a direct detection of the visual environment. ). Lynch (1960) was concerned mainly with the image of the environment, and his analysis is primarily based through vision. Several researchers argued that access to an open view has strong impact on people's satisfaction from their surrounding urban environment and their willingness to pay for a view. For example: Feitelson (1990) and Oh et al. (2002) found that landscape views had a strong impact on determining housing prices. Kfir (2001) found that a view from the dwelling units is essential for residents' satisfaction with their environment in artificial island in Japan. Kaplan and Kaplan (1989) argued that one of the components that make an environment restorative is the extent of the view, its richness and coherence. What a person could see from a window is more important than just having a window.

\subsection{The Impact of Interior Space and Functionality}

Existing visual analysis models and tools for environmental and urban systems aspire to examine external space configuration in variant ways without concerning the content and layout of the internal space. Figure (3) illustrates a Visual Exposure analysis for dwelling blocks at Bat-Galim neighbourhood, Haifa. The analysis is conducted in regard to all openings on facades illustrated in a similar way. No reference to the apartments' layout and functionality. Very similarly, the Visual Openness analysis is conducted from facades towards the view with no relevance to the internal space function behind the facade, that is to say, if the view is relevant in the bathroom as from the living room. In a table summarizing the result in previous study (Shach-Pinsley et al., 2007) it was found that $30 \%$ of the openings are less than 10 meters away from a potential viewer, and $70 \%$ have a longer distance up to 25 meters. Most 
apartments are exposed and have poor to very poor Visual Privacy. Openness to the view is also very limited as they visualise mostly their neighbour facades.

\subsection{Assumption-The Function Matters!}

The main assumption is that variant interior space layout and functionality may influence visual analysis since the need and role of Visual Exposure, Visual Openness and Perceived Density are believed to have a different impact on perception from different functions. A preliminary study was conducted using the Bat-Galim case-study, looking for the impact of variant space layouts regarding the former analysis outcomes.

\section{CASE STUDY ANALYSIS}

\subsection{The Bat-Galim Neighbourhood as a case-study}

During the 1950's the department of housing provided housing solutions for the masses of new-comers that emigrated to the young state of Israel. These housing solutions shown in a catalog for public housing were intended to reach two, sometimes contradicting goals: to be inexpensive on one hand and well designed, on the other. The design of "Minimum size apartments" was efficient and advanced for its time. A very common type of design, found all around Israel, is the row of blocks 3-4 stories in height, with 3-5 entrances and 18-30 apartments. Each apartment has a lighted hall, 2 rooms, a kitchen, a small terrace, a bathroom and a toilet. All the apartments face the North and South, the roof was not in use and the distance between blocks is minimum $22 \mathrm{~m}$. Figure 4 illustrates a common public housing floor plan. Figure 5 illustrates a schematic building block and a section.

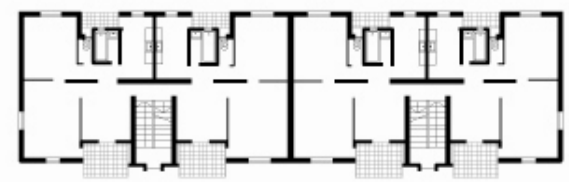

Figure 4: a common public housing floor plan.

These public houses are still in use but in most cases no changes were made since they were first inhabited and their physical condition became very poor. In most cases became undesired housing locations. At the Bat-Galim neighborhood at the seaside of Haifa the current inhabitants are weak population with very low income. The structures of the buildings are in good conditions but their appearance is decrepit. The public spaces are not in use and the general atmosphere is of neglect. These houses are in strong contrast with the adjacent imposing buildings of the regional hospital and the Medical school of the Technion, in Haifa.
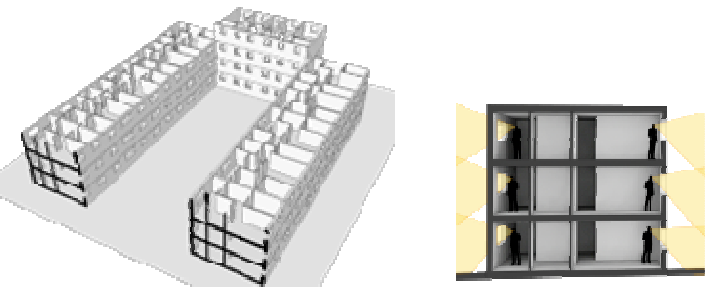

Figure 5: Existing interior space layout and functionality

\subsection{Alternative space layout and functionality}

A study focusing on alternative designs for internal space and functional distribution was carried out. Following are illustrated two examples: Figure (6) illustrates the first alternative schematic design: repetitive vertical apartments. The functional re-orientation, provides private entrances on street level, roof terraces and double-layer protection for private spaces (FisherGewirtzman, 2009). Street level do not require privacy, roof level is a big potential for openness to the view and functionalities that demand visual privacy are located on upper levels and are visually protected by layers.
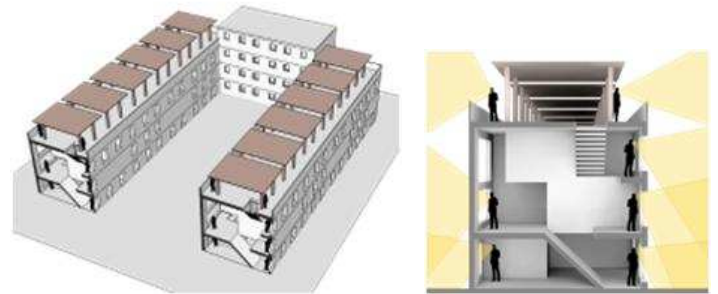

Figure 6. First alternative schematic design: repetitive vertical apartments.

Figure (7) illustrates the second alternative schematic design: repetitive vertical duplex apartments placed on top of public and commercial space located on street level; private entrances on street-level, roof terraces and a public roof promenade (Fisher-Gewirtzman, 2009). In this case street level requires high visibility and accessibility. Roof level provides private and public openness to the view. Functionalities that demand visual privacy are located on upper levels and are visually protected by layers. In this case, the high Visual Exposure considered as a great disadvantage in dwelling it converted into an advantage for the retail on street level.
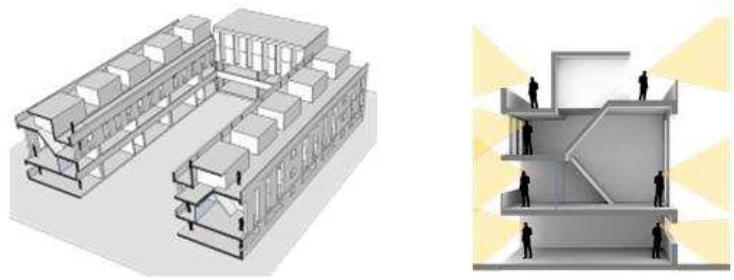

Figure 7: Second alternative schematic design: repetitive vertical duplex apartments on top of a commercial ground floor.

Since in both alternative proposals the roofs were utilized as roof terraces for public or private use, the Openness to the view analysis must be considered also on roof tops in this case. Figure (8) is comparing the illustration for visual openness to the view regarding the existing apartment's layout on the left hand-side and in the two alternatives suggesting view from roof terraces on the right.

Figure (9) illustrates all relevant floor plans for the existing design and two suggested alternatives and indicating graphically the levels of privacy provided in each space. It is clear that in all cases external terraces create a protective buffer an allows higher levels of privacy behind them. The wider and deeper they get, the better they protect. Similarly, the front and back private yards in the first alternative enable privacy on street level. 


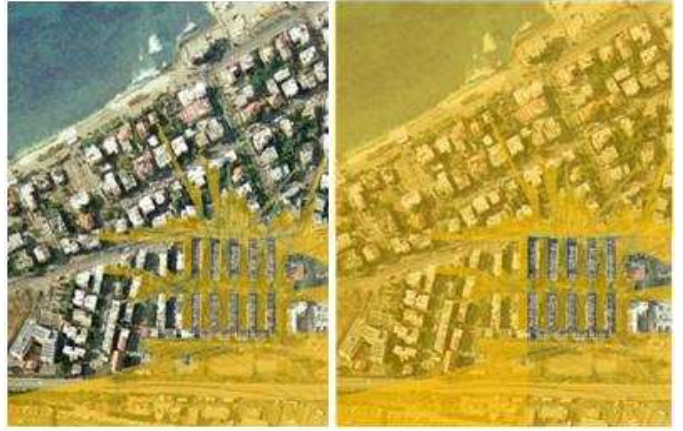

Figure 8. Comparing Visual openness. On the left regarding the existing state. On the right regarding utilized roofs
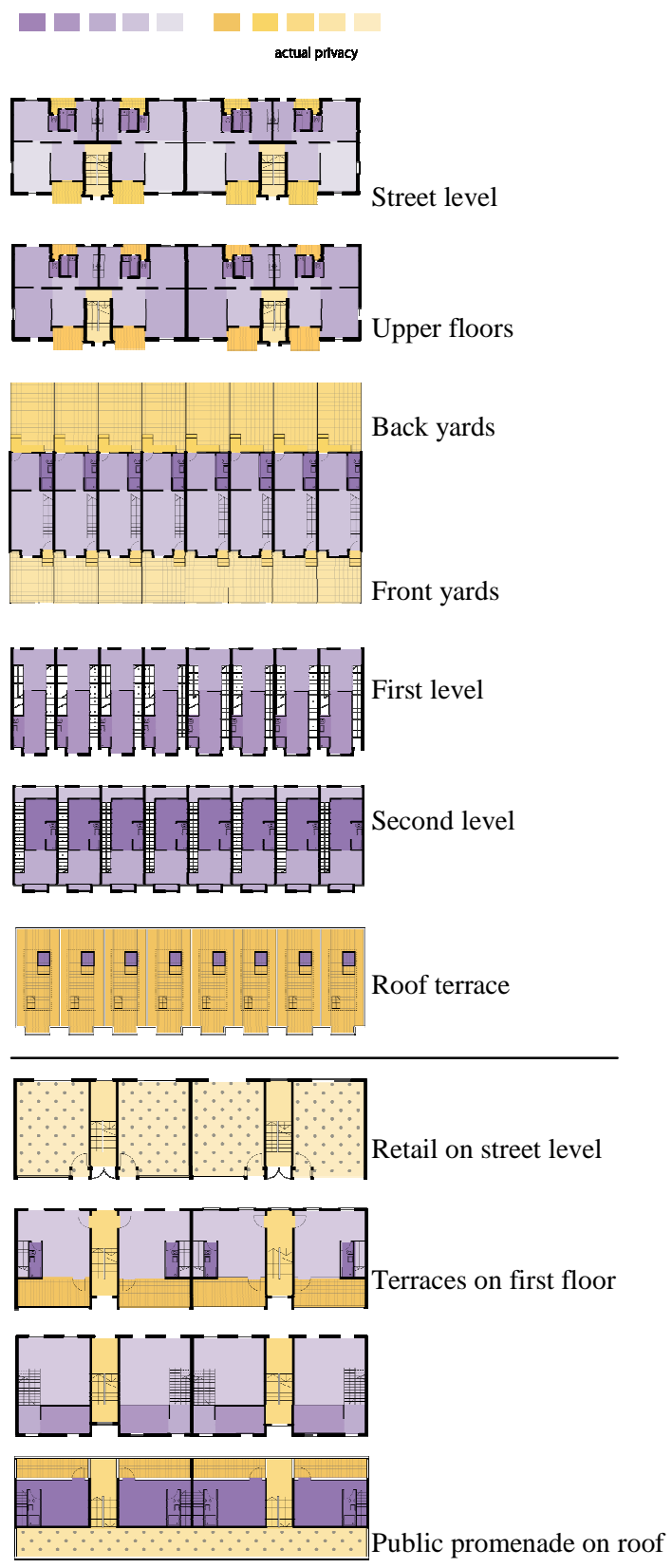

Figure 9: Privacy levels in three layouts
By observing the existing internal space layout and the two schematically designed variations emphasize that different weight should be considered for Visual Openness and Visual Privacy in different functionalities due to demand for privacy or exposure; View and the perceived density may be completely different in varied internal configurations. It also points out that visibility analysis cannot give an accurate analysis if not relating to the relevant function.

\section{DISCUSSION}

The existing Bat-Galim case-study is acting as small scale dwellings where on street level and upper floors the same repetitive apartments can be found. The ones on street level suffer from great visual exposure from their neighbors and people walking around the public space and at the same time cannot enjoy any openness to the view. On upper floors the tenants are in better position regarding privacy but have very little view and no sight to the attractive sea view. Introducing the two alternatives demonstrates how the same structure with the same analysis results can be interpreted in a completely different way.

Public and commercial functions demand a high level of visibility and accessibility, therefore locating them on street level, where Visual exposure is high would contribute to the built compound environmental quality. What is considered as disadvantage in dwelling is transformed into an advantage for retail. Entrances to vertical dwelling units, located on street level, preferably would need high levels of visual exposure to maintain home-land security, as opposed to bedrooms located on ground floor as in the existing apartments. Private functions, such as bedrooms, located on upper levels of the building, would gain a lower level of visual exposure, meaning a higher level of visual privacy. Utilizing existing roofs as roof terraces would increase the openness to the view and add significantly to the quality and attractiveness of the dwellings. There is an advantage to slim vertical dwelling units that can enjoy front and back yards, and the privacy provided on street level, together with a roof terrace providing an openness to distant view.

If comparing the built compounds' existing internal space layout with the two schematically designed variations it is obvious that the analysis outcomes may be interpreted differently and that in order to conclude a general level of environmental quality from the variant visual analyses, different weight should be considered regarding the function. On the other hand, reinterpreting the functional layout of existing building concerning visibility analysis opens up new possibilities. Since visibility-analyses would not be precise without relating to the function and internal layout. A thorough study is planed ahead. It is assumed that such a study would contribute greatly to future sustainable planning and design.

There is no doubt that recycling; regenerating by intervention in existing structures may be a fascinating and dynamic action that may install new life not only in buildings but also in city parts. This action demands creative strategies and design thinking. 


\section{BIBLIOGRAPHY}

Al-Kodmany K., (1999), Residential visual privacy: Traditional and modern architecture and urban de-sign, Journal of Urban Design, 4 (3), pp. 283-311.

Al-Kodmany, K., (2000), Women's visual privacy in traditional and modern neighborhoods in Damas-cus, Journal of Architectural and Planning Research, 17 (4), pp.283-303.

Altman, I. (1975) "The Environment and Social Behavior", Monterey, CA: Brooks/Cole.

Archea, J. (1977), The place of architecture factors in behavioral theories of privacy, Journal of Social Issues, 33 (3), pp. 116-137.

Asif S., and Malis N., (1998), High-density neighborhoods Guidelines for urban design, Ministry of housing, Jerusalem, Israel.

Batty M, 2001, "Exploring isovist fields: space and shape in architectural and urban morphology." Envi-ronment and Planning B: Planning and design, vol. 28, pages 123-150.

Benedikt M L, 1979, " To take hold of space: isovist fields" Environment and Planning B: Planning and Design, vol.6, pages 47-65.

Carmon, N., "The Phoenix Strategy for Updating Housing Stock: Preventing Neighborhood Deterioration and Promoting Sustainable Development". Journal of the American Planning Association, Vol. 68, No 4, 2002, pp. 416-434.

Day L.L., (2000), Choosing a house: The relationship between dwelling type, perception of privacy, and residential satisfaction, Journal of Planning Education and Research, 19 (3), pp. 265-275.

Efrat Zvi Ed.(2004) “The Israeli Project, Building and Architecture, 1948-1973”, Tel-Aviv Israel

Evans, G. \& Lepore, S.J. (1998). “Chronic Residential Crowding and Children's Well Being: An Ecolog-ical Perspective", Paper presented at 24th International Congress of IAAP, San Francisco.

Feitelson E, 1990, "Consumers Preferences and Wilingness to Pay For Water Related Residence in Non Urban Setting: A Vignette analysis" Regional studies Vol 26.1 pp 49-68

Fisher-Gewirtzman D. (2009) "The Visual Openness \& Visual Exposure model in regard to internal space layout and functionality."3rd ICA Workshop on Geospatial Analysis and Modeling, Gavle Sweden

Fisher-Gewirtzman D. and Wagner I. A., (2006), The 'Spatial Openness Index': an automated model for 3-D visual analysis of Urban Environments, Journal of Architecture and Planning Research, 23 (1), pp 77-89

Fisher Gewirtzman D., Shach-Pinsly D., Wagner A. I., Burt M., (2005), View Oriented Three Dimensional Visual Analysis Models for the Urban

Fisher Gewirtzman D \& Wagner I, 2003, " Spatial Openness as a Practical Metric for Evaluating Built-Up Environments" Environment and Planning B: Planning and Design Vol. 30 issue 1 pages $37-49$

Fisher Gewirtzman D, Burt M, Tzamir Y, 2003, “ A 3D Method for Comparative Evaluation of Dense Built-up Environments" Environment and Planning B: Planning and Design Vol. 30 issue 4 pages $575-587$

Gibson, J. J., (1974), The perception of the visual world, Westport, Conn.: Greenwood Press.

Gibson, J. J., (1979), The ecological approach to visual perception, Boston: Houghton Mifflin.

Hillier B, 1996, "Space is the Machine" Cambridge, UK: Cambridge
Kaplan, R., \& Kaplan, S., (1989) The experience of nature: A psychological perspective. New York: Cambridge University Press

Kfir I Z, 2001, "Research on Residential preferences and the view from the dwelling units on man-made islands in Osaka bay" Submitted in Partial fulfillment of the requirements for the degree of Doctor in En-gineering, Department of Architecture and Architectural Systems, Graduate School of Design, Tokyo, Ja-pan

Lynch, K., (1960), The Image of the City, Cambridge Mass, MIT Press.

Merry, S., (1987). "Crowding conflict and neighborhood regulation. In : Altman, I. \& Wandersman, A. (Esd). "Neighborhood and Community Environments", New York: Plenum.

Mitrany, M. (2002). "Subjective Housing Density and the Housing Context”, Ph.D. Dissertation, Haifa: Technion, Faculty of Architecture and Town

Mitrany, M. \& Churchman, A. (2004) Positive aspects of Neighborhood High Density. To Tikhnun. (He-brew, accepted). Newell, P.B., (1995), Perspectives on Privacy, Journal of Environmental Psychology, 15, pp.87-104.

Oh K. and Lee W., (2002), "Estimating the value of landscape visibility in apartment housing prices", Journal of Architectural and Planning Research, 19 (1), pp. 1-11.

Peponis J, Winerman J, Rashid M, Bafna S, Hong Kim S, 1998, "Describing Plan Configuration Accord-ing to the Covisibility of Surfaces." Environment and Planning B: Planning and Design Vol 25 pages 693-708.

Pimsler R. "Building recycling: Sustainable reuse of existing structures", New Life Journal, April-May, 2004.

Power A. " Does demolition or refurbishment of old and inefficient homes help to increase our environ-mental, social and economic viability?" Energy Policy 36, 2008 pp. 44874501.

Rapoport, A. (1975). "Toward a redefinition of density", Environment and

Shach-Pinsly D., Fisher-Gewirtzman D., Burt M., (2007), "Visual exposure analysis model; a comparative evaluation of three case studies", Urban Design International, 12, pp. 155168.

Stokols, D. (1972). "A social-psychological model of human crowding phenomena". Journal of the American Institute of Planners, 38, 72 - 83.

Sundstorm, E. (1978). "Crowding as a Sequential Process: Review of Research on the Effects of Popula-tion Density on Humans, In Baum", A., \& Epstein, Y. M. (Eds.). "Human Response to Crowding", Hills-dale, New Jersey: Lawrence Erlbaum, pp.32-116.

Thiel P., (1981), Visual awareness and design: an introductory program in conceptual awareness, percep-tual sensitivity, and basic design skills, Seattle, Wash.: University of Washington Press.

Turner A, Doxa M, O'Sullivan D, Pen A, 2001, “From isovists to visibility graphs: a methodology for the analysis of architectural space" Environment and Planning B: Planning and Design Vol 28 pages 103-122. 